\title{
Author Correction: TriQuinoline
}

\author{
Shinya Adachi 1 , Masakatsu Shibasaki \& Naoya Kumagai
}

Correction to: Nature Communications https://doi.org/10.1038/s41467-019-11818-1, published online 23 August 2019.

The original version of this article contained an error in the third paragraph of the 'Physicochemical properties of TQ' section of the Results, which incorrectly read 'The electron density $\rho\left(r_{\mathrm{c}}\right)$, the Laplacian of the electron density $\left(\nabla^{2} \rho\left(r_{\mathrm{c}}\right)\right)$, and the ratio of the curvature of the density at the BCPs $\left(\left|\lambda_{1}\right| / \lambda_{3}\right)$ have been proposed as the principal descriptors to characterise $\mathrm{CH}-\pi$ interactions, and typically fall in the ranges of $0.002<\rho\left(r_{\mathrm{c}}\right)<0.034,0.02<\nabla^{2} \rho\left(r_{\mathrm{c}}\right)<0.14$, and $\left|\lambda_{1}\right| / \lambda_{3}>1$, respectively. Among the 15 intermolecular BCPs found, 12 of these involve the protons at the 4-, 5-, and 6-positions of each quinoline unit that are geometrically close to the $\pi$-plane of [12]CPP and satisfy the aforementioned criteria, which strongly suggests that $\mathrm{CH}-\pi$ interactions play a dominant role in the formation of inclusion complex 15 (Fig. 6a)'. The correct version states ' $0.002<\rho\left(r_{\mathrm{c}}\right)<0.0034$ ' in place of ' $0.002<\rho\left(r_{\mathrm{c}}\right)<0.034$ ', ' $\left|\lambda_{1}\right| / \lambda_{3}<1$ ' in place of ' $\left|\lambda_{1}\right| / \lambda_{3}>1$ ', and ' 9 of these' in place of ' 12 of these'.

This has been corrected in both the PDF and HTML versions of the article.

Published online: 21 January 2020

\footnotetext{
(C) (1)

Open Access This article is licensed under a Creative Commons Attribution 4.0 International License, which permits use, sharing, adaptation, distribution and reproduction in any medium or format, as long as you give appropriate credit to the original author(s) and the source, provide a link to the Creative Commons license, and indicate if changes were made. The images or other third party material in this article are included in the article's Creative Commons license, unless indicated otherwise in a credit line to the material. If material is not included in the article's Creative Commons license and your intended use is not permitted by statutory regulation or exceeds the permitted use, you will need to obtain permission directly from the copyright holder. To view a copy of this license, visit http://creativecommons.org/licenses/by/4.0/.
}

(c) The Author(s) 2020 